\title{
EXPANSIÓN TERRITORIAL Y GESTIÓN INTEGRADA DE SEDES EN INACAP
}

\section{Antecedentes}

Visión institucional y misión

Desde sus orígenes, la visión de INACAP recoge la vocación de expansión territorial y la necesidad de ofrecer servicios educacionales de calidad homogénea a lo largo del país. La visión y misión que ahora se presentan deben, por mandato estratégico, regir las actividades en todas las sedes del país, y constituyen la base para medir la calidad de la enseñanza impartida ${ }^{i}$.

La visión de INACAP considera:

- Al ser humano como una persona dotada de inteligencia y voluntad para los fines educacionales que realiza. Cada persona es un ser único que, según su edad y experiencia, posee capacidades y habilidades en diferentes grados de desarrollo.

- Que sus programas de estudio, cursos, diplomados y programas de postítulo constituyen medios para potenciar el desarrollo de los individuos en cualquier momento a lo largo de su vida.

- Que las competencias laborales son las herramientas necesarias para acceder a un mejor bienestar personal y familiar, y para contribuir al desarrollo económico y social de la comunidad.

- Que el éxito profesional requiere de individuos con habilidades personales e interpersonales, además de conocimientos y competencias técnicas y de idiomas. Los profesionales deben trabajar en equipos multidisciplinarios y flexibles; deben estar

i El Instituto Profesional INACAP y la Universidad Tecnológica de Chile constituyen hoy la mayor institución de educación superior del país, con más de 54.000 alumnos matriculados en sus 25 sedes desde Arica a Punta Arenas. 
preparados para asumir riesgos y manejar la incertidumbre, y deben expresarse claramente, tanto en materias de trabajo como personales. A su vez, deben poseer sólidos valores morales que generen ambientes de confianza en estructuras organizacionales cada vez más planas y en negocios globales.

Por otra parte, la misión de INACAP plantea que esta institución:

- Buscará la formación de personas a través de la transmisión de competencias y valores, que les permitan desarrollarse como ciudadanos responsables e integrarse con autonomía y productividad en las más variadas actividades, para enfrentar el mundo globalizado en el cual Chile está inserto.

- Proveerá programas y servicios educacionales de calidad, que se adapten de manera continua, flexible y en forma modular a las necesidades de los individuos, pues reconoce la singularidad de sus motivaciones educativas a lo largo de toda su vida con el fin de alcanzar el éxito personal, contribuyendo así al crecimiento económico y social del país.

\section{Estrategias de desarrollo organizacional}

En este contexto, ha definido una serie de estrategias concretas para alcanzar los objetivos planteados de manera homogénea en todo el país. Como parte fundamental de estas estrategias, destacan varios aspectos relacionados con su desarrollo y expansión territorial:

- Mejoramiento continuo del proceso de enseñanza, centrado en el aprendizaje y en la práctica.

- Mejoramiento continuo del proceso de administración, centrándolo en la calidad del servicio a través del control de gestión.

- Foco en el éxito de los estudiantes en el mundo laboral.

- Utilización intensiva de tecnología informática en la gestión docente y administrativa. 
- Énfasis en la gestión de las sedes, entendiéndola como logro de los objetivos operativos, de posicionamiento de mercado y calidad de sus servicios.

Esta última estrategia comprende: una modificación de la estructura, pasando de una orgánica orientada al tipo de producto hacia otra con énfasis en la operación local; la implementación de un Sistema de Control de Gestión, que incluye indicadores, estándares y metas de desempeño de cada sede y el establecimiento de planes de marketing locales de acuerdo con la realidad de cada una, con el fin de complementar el marketing corporativo y alcanzar el posicionamiento de mercado deseado.

Como se puede apreciar, las cinco estrategias centrales de INACAP contienen aspectos ligados a la gestión de sedes y, en forma especial, la quinta estrategia, que se refiere exclusivamente a este aspecto, destacando así la importancia que se le atribuye al tema en el diseño organizacional.

\section{Estrategia territorial}

\section{Gestión estratégica orientada a las sedes}

Enfatiza, en distintos ámbitos, su vocación de país. Verdaderamente, las cinco estrategias mencionadas se traducen en planes de acción concretos y formas de gestión orientadas a maximizar los objetivos regionales y locales.

En efecto, la institución ha focalizado su esfuerzo en la estandarización de la calidad de la infraestructura y del servicio de Tecnologías de Información y Comunicaciones (TIC) a lo largo del país. Con esta última, sus fronteras físicas se eliminaron, ya que los alumnos, docentes y, en general, todo usuario que interactúa con INACAP pueden acceder desde cualquier lugar que tenga una conexión a Internet. 
Respecto de la estrategia "énfasis en la gestión de las sedes", entendiéndola como el logro de los objetivos operativos, de posicionamiento de mercado y calidad de sus servicios, en 2003 se adecuó la estructura organizacional, pasando de una orgánica orientada al tipo de producto a otra con énfasis en la operación local y la calidad de los servicios.

Desde ese momento, se redefine el rol de los vicerrectores de sede que hasta entonces estaban fuertemente influidos por una estructura matricial.

Actualmente, y consecuente con la reestructuración antes señalada, se ha implementado un modelo con énfasis en la gestión de las sedes, bajo una supervisión de las vicerrectorías nacionales de sedes, con miras a la ejecución de las políticas y objetivos planteados por el Consejo Directivo de INACAP.

En este sentido, los roles que han cumplido estos vicerrectores abarcan las dimensiones de dirección, coordinación y control de la gestión operativa y de calidad de las distintas actividades desarrolladas en los ámbitos que define la rectoría. Las sedes ejecutan las acciones que les permiten un sostenido posicionamiento en sus mercados respectivos, con un eficaz aprovechamiento de sus sinergias. Con el objetivo de complementar el marketing corporativo y alcanzar el posicionamiento de mercado deseado, se han establecido planes de marketing locales de acuerdo con la realidad de cada una.

Los resultados de esta estrategia de posicionamiento y fortalecimiento territorial están a la vista. La tabla $\mathrm{N}^{\circ} 1$ muestra la evolución de la matrícula nacional en los últimos años.

Tabla Nº 1: Evolución de la matrícula de INACAP entre los años 1999 y 2006

\begin{tabular}{|c|c|c|c|c|c|c|c|c|}
\hline Año & 1999 & 2000 & 2001 & 2002 & 2003 & 2004 & 2005 & 2006 \\
\hline Total & 41.539 & 44.553 & 47.608 & 48.790 & 48.062 & 45.609 & 47.932 & 54.189 \\
\hline
\end{tabular}

Fuente: Años 1999 a 2006 corresponden al semestre Otoño de cada año. 


\section{Gestión presupuestaria}

En relación con la gestión presupuestaria, INACAP ha implementado un modelo que enfatiza la gestión de las sedes. En efecto, anualmente se lleva a cabo un proceso de elaboración del Presupuesto Anual que, en su parte pertinente, establece las siguientes etapas:

- Propuesta de nuevos programas de estudio, metas y tarifas de las sedes.

- Formulación del modelo presupuestario.

- Apertura de cada línea de información del presupuesto aprobado a cargo de las propias sedes.

\section{Gestión académica orientada a la calidad}

Respecto de la gestión académica, la institución ha implementado también un modelo que recoge las particularidades regionales y locales de cada sede, al tiempo que garantiza la calidad y homogeneidad de los contenidos, programas y docencia a nivel nacional.

Las actividades de desarrollo, creación y actualización de programas de estudio, con sus perfiles de egreso y el correspondiente desarrollo curricular, se realizan corporativamente en la Vicerrectoría Académica, para luego ponerlos a disposición de las sedes que decidan impartirlos, de acuerdo con las propias necesidades y realidad de mercado.

La apertura de un programa de estudio en una sede constituye otro proceso en el que se analiza información local o regional, aplicándose criterios de evaluación económica para adoptar la decisión. La asignación de recursos para ello se realiza a través del proceso presupuestario anual, que tiene en consideración los recursos para la normal operación de la sede y la provisión de los servicios educacionales necesarios.

El proceso de enseñanza se lleva a cabo en las sedes que imparten los programas. Este considera, como características 
relevantes, los métodos pedagógicos, los procedimientos de evaluación de aprendizajes y el uso de tecnologías que permiten el logro de aprendizajes significativos.

La Vicerrectoría Académica dispone de un equipo de asesores de programas de estudio responsables de velar por la actualización y pertinencia de un grupo de programas que se le asignan.

A continuación, se describen algunos procedimientos específicos de gestión, que se aplican en distintos ámbitos del quehacer de INACAP en todo el país.

\section{Proceso de evaluación docente y administrativa}

A partir de 2000, el instituto realiza cada semestre una Evaluación de Desempeño Docente, como parte de su proceso de gestión de calidad destinado también a medir la incidencia de este desempeño en los logros de aprendizaje de los estudiantes. Consiste en la aplicación de encuestas de opinión que recogen las percepciones de alumnos, directores de carrera y de los propios docentes.

La información permite que el docente identifique sus fortalezas y debilidades y, al mismo tiempo, las sedes pueden definir e implementar acciones que mantengan y/o mejoren la calidad de sus servicios educacionales.

Se miden tres aspectos que inciden en los aprendizajes de los alumnos: el dominio de los contenidos, el ambiente de enseñanza y las estrategias favorables para el aprendizaje. Existe una aplicación en SIGA que se denomina "Sistema de Evaluación en Línea del Desempeño Docente" para que los alumnos, docentes y directores de carrera contesten las encuestas a través de Internet e Intranet, marcando un hito en el uso de Tecnologías de Información (TICs).

La cobertura de respuestas ha ido sistemáticamente en alza en las tres fuentes de opinión, llegando a un 73,6 \% de cobertura 
en el semestre Primavera 2005. El aspecto mejor evaluado por los alumnos es el Dominio de los Contenidos de Aprendizaje, con un $84,3 \%$ de opiniones favorables.

Como complemento a esta evaluación, se aplica desde 2000 una Pauta de Observación de Clases con el fin de reforzar las buenas prácticas docentes. El instrumento mide siete variables: Responsabilidad y Organización del profesor, Orientación de los Objetivos, Tratamiento del Contenido, Utilización de Recursos Didácticos, Tratamiento Metodológico, Relaciones Interpersonales con los Alumnos, Evaluación y Retroalimentación.

Por otra parte, y con el fin de verificar la calidad y homogeneidad de los aprendizajes fundamentales, a partir de 2001 se aplican, además, las Evaluaciones Nacionales Estandarizadas, a través de instrumentos elaborados centralizadamente por equipos de especialistas técnicos y pedagógicos, focalizados en los aprendizajes esperados e indicadores de aprendizaje de los respectivos programas.

Las asignaturas que se evalúan con este formato se seleccionan considerando su relevancia en el perfil de egreso y el impacto en cuanto a la cantidad de alumnos y programas de estudio evaluados en cada aplicación. De acuerdo con este criterio, la última prueba parcial tiene el carácter de Prueba Nacional y se aplica en un mismo día en las sedes de la institución en que se imparte la asignatura.

\section{Creación de programas de estudio}

Los programas y planes de estudio que ofrece INACAP son consistentes con la misión y objetivos institucionales en cuanto a su calidad, pertinencia y empleabilidad. Continuamente, la institución revisa los aspectos relativos a la provisión de sus programas para asegurar su actualización y vigencia de acuerdo con los requerimientos y condiciones cambiantes del mercado. La 
generación de nuevos programas de estudio se valida mediante los mismos procesos.

\section{La enseñanza del idioma inglés}

La Vicerrectoría Académica, desde inicios de 2005 ha puesto a disposición de sus alumnos, docentes y público en general un Centro de Recursos Virtuales English Corner, destinado a reforzar, complementar y mejorar la enseñanza y el aprendizaje del inglés, de una manera novedosa y entretenida. Esta iniciativa se inserta dentro del objetivo institucional de innovación tecnológica y formación por competencias, ya que, en la actualidad, su dominio es una herramienta de comunicación de excelencia que permite el acceso a mejores empleos con remuneraciones más altas.

\section{Programa de apoyo docente}

La capacitación continua de los docentes, tendiente al mejoramiento de la calidad de la enseñanza, fue el objetivo de crear los PAD (Programa de Apoyo Docente) en 2000.

Los programas contemplan entre otras temáticas:

- Modelos de enseñanza.

- Planificación de actividades docentes.

- Metodología centrada en la acción.

- Objetivos transversales.

- Instrumentos de evaluación.

- Desarrollo de página web educativa.

- Formación y evaluación de competencias.

- Videos educativos.

\section{Proceso de apertura de nuevos programas de estudio}

Se orienta a dar cumplimiento a las estrategia de desarrollo y programas de acción cuyos enunciados son: "generar nuevos 
programas de estudio de acuerdo con las necesidades de desarrollo económico y social del país" y "homogeneización de la calidad de la infraestructura y de la calidad del servicio a lo largo del país", respectivamente.

Abrir un determinado programa tiene por objeto satisfacer oportunamente la demanda de profesionales en la región o ciudad que los requiera. Consiste en sancionar la solicitud de una sede para impartir un programa de estudio ya creado y que se está impartiendo en otras. Los antecedentes que se tienen en cuenta dicen relación con un análisis de mercado y de la competencia, proyección de alumnos y evaluación económica.

La Vicerrectoría Académica revisa estos antecedentes y se pronuncia respecto al estudio de mercado, la proyección de alumnos, equipamiento e infraestructura requerida (cumplimiento del estándar para laboratorios y talleres), recursos humanos, análisis económico y otros antecedentes que aporten a la decisión de la apertura. Por otra parte, la Gerencia Inmobiliaria revisa y se pronuncia respecto de la capacidad instalada. Finalmente, los informes emitidos son considerados por las vicerrectorías nacionales de sedes, las que ajustan sus propuestas en concordancia con las eventuales observaciones de las unidades revisoras citadas, previo a su aprobación final por la rectoría.

\section{Conclusiones}

El modelo de gestión territorial de INACAP ha permitido una expansión significativa de la matrícula y las sedes en todo el país, sin comprometer la calidad y homogeneidad de la enseñanza impartida. Al contrario, estimamos que el modelo de gestión ha sido la clave para lograr el éxito institucional significativo de los últimos años, al abrir espacio para la localización de contenidos y programas sin dejar de lado las sinergias que cada sede logra al pertenecer a una institución de carácter nacional que, en mucho sentidos, es un verdadero centro de servicios compartidos. Este 
modelo otorga ventajas claras al momento de insertarse en el mercado educacional chileno y garantiza que el compromiso de la institución con sus alumnos y la sociedad se cumplirán fielmente.

Recibido: 16 de mayo de 2006

Aceptado: 8 de junio de 2006 